ing characters : sp. gr. 1030, normal appearance to the eye, no sugar, but a distinct trace of albumen, both to heat and nitric acid (urine passed at 2 P.M.). My report was as follows : "I think this case must be postponed, so far, at least, as to admit of inquiries in detail as to the albuminuria. Apart from this, I see nothing in the case to render the life intligible."

A second sample of urine was obtained on Feb. 12th which had exactly the same characters, sp. gr. 1024. I then placed the inquiry in the hands of his medical attendant, with the general instruction that this was a question to be considered, not in the interests of the insurance office, but of the proposer himself. The result was that he returned on Bept. 27th, 1892, with a verbal report that his medical attendant had found the urine to contain a trace of albumen on several occasions after I had notified the fact to him, but on other occasions had found it free-no exact statements as to these occasions or as to the cyclic character of the albuminuria. On this I reported further as follows: "This life is in every respect unexceptionable, if we can take it as a rule to be followed that a very small trace of albumen in the urine, nther circumstances being favourable, is not to be a bar to insurance. I am not personally quite of that opinion, though I admit circumstances under which accidental and occasional impregnations of serum albumen may not seriously damage a life from the insurance point of view. How far this is such a case will appear from the following summary: On Feb. 4th and again on the 12th $I$ found the trace above mentioned in the urine of this gentleman. The same is the case to-day. Urine passed at half-past twelve normal to appearance in all respects, but with quite unequivocal trace of albumen by heat with acetic acid and by Roberts's solution of magnesium sulphate with nitric acid employed by the contact method." I then gave the medical attendant's verbal report as above, which he afterwards (Oct. 10th) reduced to writing as follows: " $\mathrm{X}$ supplied me with a sample of his urine weekly during the months of May, June and July to examine for albumen. In every sample $I$ was able by the ordinary tests to detect a very small amount. I kept him under treatment for that time, but the quantity of albumen remained much the same. During the last two months I had several opportunities of examining his urine and found the quantity distinctly less, particularly so in the last two samples, where I had a difficulty in detecting even the slightest trace."

At a quite recent date in the end of February, 1893, this proposer called once more at the office and passed a sample of urine, which did not differ in any essential particular from the preceding as examined by me. He brought the following note from his medical attendant: " $\mathrm{X}-$ has been supplying me with samples of his urine regularly every week or ten days since the date of last report. I have made a careful examination in every instance-microscopically and with the other tests for albumen, - with the result that I am perfectly satisfied there is no kidney disease in his case. In several of the samples sent in I could not detect any albumen at all, and the quantity, when it could be traced, was so insignificant that I consider it a waste of time to prolong the examination." Still, there the albumen remains, according to my examination in February, 1893, exactly as it was in Yebruary, 1892. I have already said, in public, at Birming. ham and elsewhere, in discussions on the subject, that I cannot but regard the presence of serum albumen (reacting to heat and nitric acid) to this small extent and with this degree of persistency as a danger signal. If this statement of this case is disputed, on anything like reasonable grounds, by those who advocate a " physiological albuminuria," I may have something more to say on the subject. Meanwhile I do not wish it to be supposed that I think it follows, from the expression used above, that this man has Bright's disease, or that he is very likely to die soon. A danger signal may avert danger rather than bring danger. Nay, a danger signal may be disregarded and yet no train be wrecked. But, still, there it is, and from the insurance point of view I think it eught not to be disregarded.

I am, Sirs, yours faithfully,

$\begin{array}{ll}\text { Glasgow, March 7th, } 1893 . & \text { W. T. GAIRDNER, M.D. }\end{array}$

\section{PROGNOSIS IN ALBUMINURIA.}

\section{To the Editors of THE LANCET.}

SIRS,-Your excellent advice that the time has arrived for a thorough reinvestigation of the prognosis of albuminuria will be shared by manymen. I think that most help will be obtained from men who have kept private records of their cases for years rather than from hospital or even insurance records. If some method could be devised for collecting and analysing these notes an invaluable stock of renal knowledge would be available. The prognosis of heart disease has received more attention than that of albuminuria, and it will be in the recollection of many that the former, at the instigation of the Collective Investigation Committee, was ably introduced by Sir Andrew Clark and fully discussed at the annual meeting of the British Medical Association in Brighton in 1886. One starts in practice with a horror that every case of albuminuria is going to be fatal. After having scared a number of people needlessly, one gradually settles down to a more hopeful view of the presence of albuminous urine, which is comforting to the patient and beneficial to the doctor. At present it is impossible to say how many cases of early albuminuria develop Bright's disease and how many recover ; but there is a point which must have struck several men much engaged in private practice-namely, the small number of deaths that occur from Bright's disease compared with the large number of cases of albuminuria met with. This appears to support the view, at any rate indirectly, that a good number of people recover. Some years ago I wrote to THE LANCET in reference to the "loading" of albuminuric cases, either in respect to the adding of years or of money. A fairer method seems to be that in which no extra premium is charged, but if the assured die previously to the age to which, as a first-class life, he might be expected to live, an equivalent deduction should be made from the amount assured, the deduction decreasing every year the assured lives, and if the assured should live as long as a first-class life is expected to live, the debt would be finally extinguished, and the amount of the original assurance would be paid in full at his death.

I am, Sirs, your obedient servant,

Folkestone, March 7th, 1898. W. J. TYSON.

\section{INCIDENTS IN CHLOROFORMISATION.} To the Editors of THE LANCET.

SiRs, - On Sunday, Feb. 19th, I performed circumcision on a boy of eleven years, who had suffered for years from nocturnal incontinence. Dr. Thorpe administered chloroform on a napkin. The boy was very frightened previously to the operation, but he took the anasthetic without struggling, and was speedily brought under. I had completed the operation, save the tying of the last stitch, when my attention was drawn to the patient's breathing; the respiration was very shallow, and as I looked it ceased. The nurse, an experienced woman, immediately exclaimed, "Oh, he is dead!" Dr. Thorpe quickly removed the boy's shirt, which was his only article of clothing except his stockings, and I seized the ankles, drew them over my shoulders, and, thus suspended, carried him about as well as the limited dimensions of the room permitted. After some minutes of this I placed him on the bed and we performed artificial respiration, drawing out his tongue at the same time. In about ten minutes we were rewarded by a faint gasp. The chest walls were very thin and the heart was noticed to be feebly beating, though no pulse was felt. By continuing the artificial respiration the breathing improved, and the abdomen rose and fell with each respiration. The breathing, however, again died away; the abdominal wall was flat and perfectly still. Dr. Thorpe then suspended him as before, and carried him through the roum for from five to ten minutes. I observed the face become congested, and once more we resumed artificial respiration, to which he again responded after what seemed an age ; but again we were disappointed, as respiration once more ceased. Four times in all was he suspended; the third time he vomited some unmasticated and undigested orange, which was with difficulty removed from his throat. Finally, I left him breathing comfortably after three-quarters of an hour's exertion. From the commencement of the anæsthetic until the collapse was about twelve minutes, and Dr. Thorpe informs me the quantity of chloroform used was two drachms. The boy is now well.

\section{I am, Sirs, yours truly,}

Stourport, March 7th, 1893 .

$$
\text { DONALD C. MARTiN, A.M., M.D. }
$$

\section{THE VACCINATION PROBLEM.}

To the Editors of THE LANCET.

SIRS, - Will you permit me to express a hope that medical practitioners will not lose sight of your suggestion with regard 